\title{
OPTIMIZATION OF ROUTES FOR TRANSPORTATION OF MUNICIPAL SOLID WASTE IN BAHADURGARH CITY OF HARYANA
}

\author{
Sushila Devi ${ }^{1}$ and S.K. Bansal ${ }^{2}$ \\ ${ }^{1}$ Ph.D. Scholar ${ }^{2}$ Professor, Department of Geography \\ Maharshi Dayanand University Rohtak, Haryana, India \\ Email: bansal_sudhir@rediffmail.com
}

\begin{abstract}
An important functional element in the solid waste management system is the transportation of the solid waste from the source to its' ultimate fate. An effective solid waste management system is needed to ensure better human health and safety in any urban locality. More often, it appears difficult to minimize two variables - cost and environmental impact simultaneously. Hence, the balance that needs to be struck is to reduce the overall environmental impact of the waste management system as far as possible within an acceptable cost limit. (Ghose et al., 2006). Therefore, any improvement in the collection system can reduce overall cost significantly. In this paper, efforts have been made to find out an optimal MSW collection and transportation scheme that focus on the problem of minimizing the length of each waste collection and transportation route in Bahadurgarh city of Haryana. GIS has been found to play a significant role in the domain of finding the optimal routes for the transportation of municipal solid waste to the recovery stations or the disposal sites. The optimal routes have been optimized on the basis of various criteria e.g. location of collection points, width of roads and traffic volume etc. The proposed scheme is able to reduce more than 30 percent of the total waste collection path length.
\end{abstract}

Key words: Municipal Solid Waste, Waste Management System, Transportation

\section{Introduction}

Solid waste collection and its transportation involves storage at the generation and pick-up points pick up by the crew, trucks driving around the neighbourhood, and truck transport to a transfer station or disposal point. The collection of municipal solid waste is a difficult, complex and costly affair. Collection of solid waste typically, consumes 60-80 percent of the total solid waste budget of a community. Therefore, any improvement in the collection system can reduce overall cost significantly (Gaurav K. Singh, et al, 2014). The present situation of direct dumping of the waste without proper inspection and separation leaves a serious impact of environmental pollution causing a tremendous growth in health-related problems [Bhambulkar, A. V., 2011]. It is very essential to synchronize the whole operation of collection of waste with the transportation for effective management of waste and for achieving cost efficiency in the process of waste management.

\section{Study Area}

Bahadurgarh is among the most rapidly developing cities in the National Capital Region. Bahadurgarh town is situated on Delhi-Hisar National Highway number 9 at a distance of 2 Kilometres from Tikri border (Delhi). It is located on the intersection of 76055'25" East longitude and 28.43'50" North latitude. Population of the city is growing day by day due to its location, availability of resources and job opportunities. But lack of commensurate investment in urban infrastructure and services has resulted in an overall deterioration of urban quality of life. The problem of solid waste can be seen and smell at every nook and corner of the city. So, it is significant to identify and select optimal routes for the transportation of waste. So that it can reduce the total expenditure of time and money. An 
economic and environment friendly transportation is an integral part of the whole municipal solid waste management system.

\section{Objectives}

The present study mainly aims to find optimal transportation routes from the waste bins and the collection points to the disposal site located at Nayagaon in Bahadurgarh city.

\section{Materials and Methods}

The present study is based on both spatial and non-spatial data which was obtained from the Municipal Council office and field. Spatial data such as Top sheets at a scale of 1:50,000, Municipal Council map of Bahadurgarh city, town and Country Planning Map of Bahadurgarh city and non-spatial data related to the existing SWM system detail i. e. generation of waste, number of storage bins, number and type of vehicles for transportation of waste, transportation routes and waste disposal site etc. has been obtained from the sanitary department of the BMC. The optimal routes have been optimized on the basis of various criteria as follows:

- Location of collection points

- Width of roads

- Amount of waste generation

- Traffic volume

- location of schools, colleges and religious places

- disposal site

GIS has been used to analyse all the collected data. It consists of a geo-referenced spatial database, which includes all required parameters for MSWM. These parameters involve sanitary wards, collection points, transportation road network, as well as the location and capacity of disposal sites.

\section{Transportation of Waste in Bahadurgarh}

The ultimate fate of MSW in Bahadurgarh is reaching to the disposal site and no recovery or recycling station comes in between from the collection point to the disposal site. It is the responsibility of Municipal Council of Bahadurgarh to collect the waste from different waste collection points and transport it to the bigger collection points or directly to the disposal site at Nayagaon through whatever the vehicular fleet available to do the same. There are no fixed routes of the vehicles for the transportation of waste from different collection points in the city to the disposal site at Nayagaon. The transporting vehicles collect the waste from the collection points on the basis of the demand of local residents and amount of waste generated and then deposit it at the disposal site at Nayagaon. The transporting vehicles play an important role in success of the whole solid waste management system. The collection efficiency of the total waste completely depends on the type and capacity of the transporting vehicles. The transport fleet of the BMC consists of the following:

Table: 01 Vehicular Fleet of Bahadurgarh Municipal Council

\begin{tabular}{|c|l|l|}
\hline Number of Vehicles & \multicolumn{1}{|c|}{ Type } & \multicolumn{1}{c|}{ Size } \\
\hline 10 & Big tractors & $6 / 11^{*} 4$ feet height (approx. 2.5 tons) \\
\hline 1 & Swaraj Mazda & 3.3 cum (approx. 3 ton) \\
\hline 10 & Mini Tractors & $6 / 6(1$ ton) \\
\hline 15 & Cycle Cart & \\
\hline 2 & Loaders & \\
\hline 1 & JCB & \\
\hline
\end{tabular}

Source: Bahadurgarh Municipal Council, Bahadugarh, 2017

The ten big tractors take at least two trips daily from the collection points to the disposal site and more trips depend upon the amount of waste on collection points. Mini tractors and cycle carts are used for the house to house collection of waste. Two loaders 
are used to lift the waste from the open collection points and load that waste in the big tractors for transportation to the disposal site.

\section{Requirement of Waste Transporting Vehicles}

It has become clear after analysing the existing system of waste collection and transportation that there is a dearth of vehicles to improve the collection efficiency. At the onset in the direction to improvement, requirement of five trucks with hydraulic container with a capacity of minimum $7 \mathrm{MT}$ and if possible, with cover.

\section{Optimization of Waste Collection and Transportation}

The development of optimal routing scenarios is a very complex task, based on various selective criteria, most of which are spatial in nature. Keeping in mind the criteria, two types of routes have been optimized in Bahadurgarh city:

\section{Route Type 1}

The first are the smaller routes which aim to assist in the primary collection of waste from the smaller waste bins and disposing it in the larger cemented waste bins. The transporting vehicles on these routes will be of small size as possessed by the BMC. The mini tractors with the capacity of 1 to $1.5 \mathrm{MT}$ will move on these roads as in the areas across line par do not have wider roads to move a bigger vehicle than these mini tractors. These tractors are used for the door to door collection of waste in the city. These mini tractors can carry on their work during the day in the residential areas as there is no problem of traffic congestion in these areas. The Figure: 1 shows smaller routes connecting all the smaller waste bins to the larger ones.

\section{Figure 01: Transportation Routes from Smaller to Larger Waste Bins Bahadurgarh City}

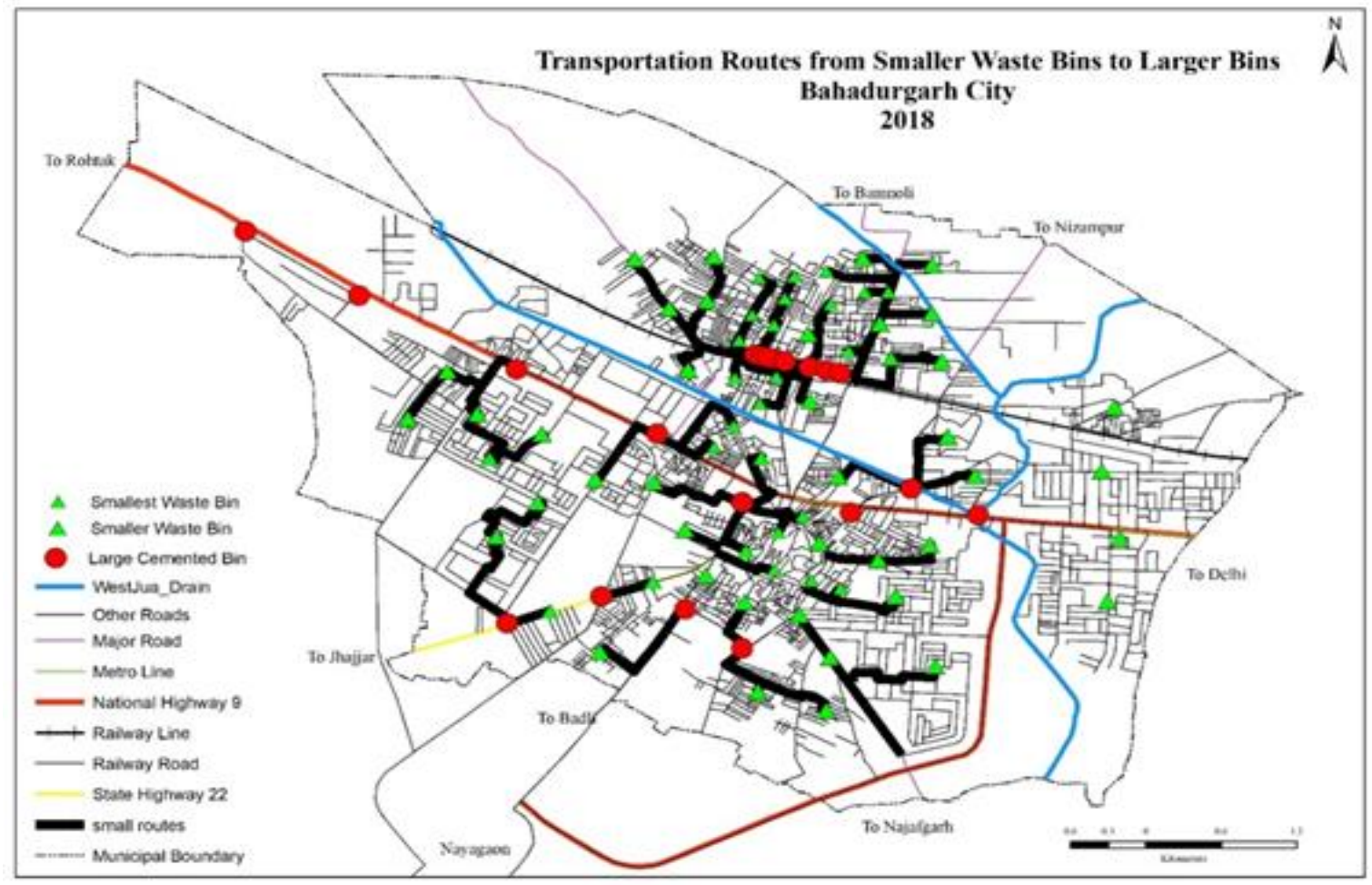

\section{Route Type 2}

The second type of routes are the longer routes which will connect all the larger cemented waste bins to the disposal site situated at Nayagaon. These longer routes will not cross the busiest roads of the city except few exceptions where there is no chance for adopting any other route. 
Figure 02: Optimal Transportation Routes Bahadurgarh City

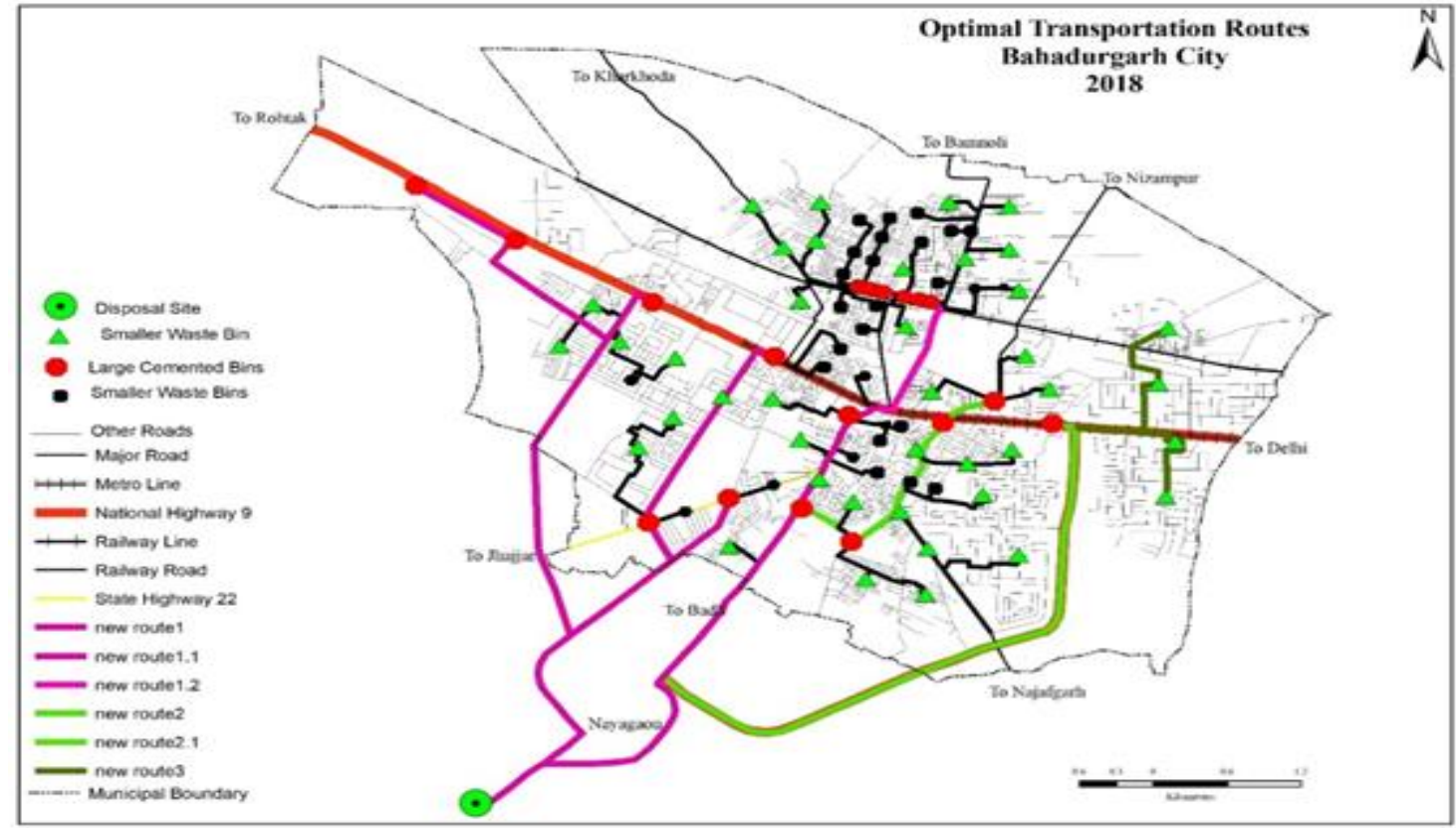

\section{Cleaning of Waste Bins}

The larger cemented waste bins are to be cleared twice a day. Once in early morning before 8:00 o'clock and once on the onset of evening in between 3:00 to 4:00 PM. During these collection hours, the traffic on the major roads will on the least especially in the morning. The proposed 5 trucks with larger capacity of minimum 5 MT capacity and the existing big tractor-trailers will move on the roads for the waste collection from these larger cemented waste bins. The loading time at each collection point is assumed to be 20 minutes when the loading is done manually. Two sanitary workers will accompany the truck along with one driver. The speed limit of the vehicles will be $20 \mathrm{~km} / \mathrm{hour}$. The table; 2 shows the approximate time to be taken by one vehicle from the collection point to reach the disposal site situated at Nayagaon. The loading time is included in the total time to be taken by all the vehicles and is considered to be 20 minutes for one vehicle.

Table 02: Time to be Taken by the vehicles to reach Disposal Site (approx.)

\begin{tabular}{|l|c|c|}
\hline Location of Collection Point & $\begin{array}{c}\text { Distance from Disposal } \\
\text { Site (in kms.) }\end{array}$ & $\begin{array}{c}\text { Time to be taken to reach } \\
\text { Disposal Site (in minutes) }\end{array}$ \\
\hline Sec-16 A+B & 8.8 & 46 \\
\hline City Park & 9.4 & 48 \\
\hline Civil Hospital & 5.9 & 38 \\
\hline Krishna Nagar & 4.2 & 33 \\
\hline Old Court Road & 5.0 & 35 \\
\hline Line Par & 7.1 & 42 \\
\hline Line Par & 7.0 & 41 \\
\hline Ramnagar & 7.1 & 42 \\
\hline Bus stand & 6.3 & 40 \\
\hline Western Jua Drain & 8.0 & 45 \\
\hline Mela Ground (Badli road) & 4.3 & 33 \\
\hline Mela Ground (Ballor road) & 4.8 & 35 \\
\hline
\end{tabular}

The collection points located at the Mela ground on Badli road and Ballor road can be cleared at any time in the day after clearing the waste from the above-mentioned collection points and before the repeat clearing starts as there are no issues related to traffic congestion. 


\section{Conclusion}

The transportation of municipal solid waste is an important and obligatory service to be provided to the residents of the city by the authorities. The process of transportation of waste starts from the collection of waste from the household and it leads to the community bins and then to the disposal site. Here, an optimal routing pattern was identified that turned out to be profitable and consume less time compared to the existing execution route for the transportation of municipal solid waste. As it is clear from various studies that the transportation of alone consumes more than 50 percent of the total sanitary budget, this small improvement in the collection operation can result in a significant saving in the total cost and our environment as well.

\section{References}

1. Bhambulkar, A. V., \& Khedikar, I. P. (2011). Municipal solid waste (MSW) collection route for Laxmi Nagar by geographical information system (GIS). International Journal of Advanced Engineering Technology, 2(4), 48-53.

2. Chimote, K., \& Bhabhulkar, A. (2012, March). Municipal Solid Waste (MSW) Collection by Geographical Information System (GIS). In National Conference on Innovative Paradigms in Engineering and Technology. IJCA, New York (pp. 1-4).

3. Chiplunkar, A.V. and et al (1981): "Optimization of refuse collection systems", Journal of Environmental Engineering Division, ASCE 107 (EE6), pp. 1203-1211.

4. Danbuzu, L. A. S., and et al (2014): "Spatial Distribution of Solid Waste Collection Points Using GIS Approach in Urban Katsina, Katsina State, Nigeria", American Journal of Engineering Research, Vol. 3 (7), pp 107-116.

5. Das, K., and Sikder S. K. (2008): "Application of GIS in Urban Solid Waste Management: A Case study in KCC. In Proceedings of the National Seminar on Solid Waste ManagementWaste Safe.

6. Das, S., \& Bhattacharyya, B. K. (2015). "Optimization of municipal solid waste collection and transportation routes", Waste Management, Vol 43, pp 9-18.

7. Gaurav, K. Singh and et al (2014): "Solid Waste Management: Its Sources, Collection, Transportation and Recycling", International Journal of Environmental Science and Development, Vol. 5, No. 4, pp. 347-351.

8. Ghose, M. K., Dikshit, A. K., \& Sharma, S. K. (2006). A GIS based transportation model for solid waste disposal-A case study on Asansol municipality. Waste management, 26(11), 1287-1293.

9. Gupta, N., Yadav, K. K., \& Kumar, V. (2015). A review on current status of municipal solid waste management in India. Journal of Environmental Sciences, 37, 206-217.

10. Hareesh K.B., Manjunath N.T., Nagarajappa D.P., (2015). Route Optimization of Municipal Solid Waste for Davangere City Using GIS. International Journal of Innovative Research in Science, Engineering and Technology, 4(6), 3834-3843.

11. Hazra, T., \& Goel, S. (2009). Solid waste management in Kolkata, India: Practices and challenges. Waste management, 29(1), 470-478.

12. Kanchanabhan, T. E., Abbas Mohaideen, J., Srinivasan, S., \& KalyanaSundaram, V. L. (2011). Optimum municipal solid waste collection using geographical information system (GIS) and vehicle tracking for Pallavapuram municipality. Waste Management \& Research, 29(3), 323-339.

13. Khan, N. A. (2014). "Perspectives of Transport and Disposal of Municipal Solid Waste in Srinagar City", International Journal of Engineering Research and General Science, Volume 2, Issue 4, pp.238-251, ISSN 2091-2730.

14. Malakahmad, A., Bakri, P. M., Mokhtar, M. R. M., \& Khalil, N. (2014). Solid waste collection routes optimization via GIS techniques in Ipoh city, Malaysia. Procedia Engineering, 77, 20 27.

15. Sharholy, M., Ahmad, K., Vaishya, R. C., \& Gupta, R. D. (2007). Municipal solid waste characteristics and management in Allahabad, India. Waste management, 27(4), 490-496.

16. Shastri, N., Verma, S., \& Patel, J. (2014). Municipal solid waste management of Anand City using GIS technique. Int. J. Eng. Res. Technol, 3(7), 707-71.7

17. Shoba, B., \& Rasappan, K. (2013). Application of GIS in solid waste management for Coimbatore city. International Journal of Scientific and Research Publications, 3(10), 1-4. 